\title{
A blinded palatability study comparing two extensively hydrolysed infant formulas, used for the dietary management of cows' milk allergy in Ireland
}

\author{
E. O'Carroll ${ }^{1}$, M. Redmond ${ }^{2}$, J.L. O’Neill' ${ }^{2}$, E. Shannon ${ }^{2}$ and A. Regan ${ }^{2}$ \\ ${ }^{1}$ University College Dublin, Belfield, Dublin 4, Republic of Ireland and ${ }^{2}$ Danone Nutricia Early Life Nutrition, Block 1 \\ Deansgrange Business Park, Deansgrange, Co. Dublin, Republic of Ireland.
}

Cows' milk allergy occurs when the immune system reacts to one or more of the proteins contained in cows' milk and affects approximately $2-7.5 \%$ of infants ${ }^{(1-3)}$. Extensively hydrolysed formulas are the preferred option in formula fed infants and an amino acid based formula for more severe cases ${ }^{(4)}$. Research has shown that palatability of extensively hydrolysed formulas are important in relation to the volume consumed by the infant, with a whey hydrolysate being reported to result in larger intakes compared to a casein hydrolysate ${ }^{(5)}$.

The aim of this study was to determine if a sample of healthcare professionals in Ireland considered palatability an important factor when prescribing hydrolysates for cows' milk allergy and to evaluate the palatability of an extensively hydrolysed whey based, reduced lactose formula (formula A) compared to an extensively hydrolysed casein based lactose free formula (formula B).

A blind taste test comparing the formulas A and B was carried out on a sample of healthcare professionals $(n=192)($ doctors $38 \%$, nurses $39 \%$ and dietitians $23 \%$ ). These health care professionals were asked which sample they found more palatable and also whether they considered palatability an important factor when prescribing a hypo allergenic formula.

This study found that $93 \%(\mathrm{n}=178)$ of the healthcare professionals felt that formula A was more palatable than formula B. Furthermore, $94 \%(n=144)$ considered palatability an important factor when prescribing an extensively hydrolysed formula.

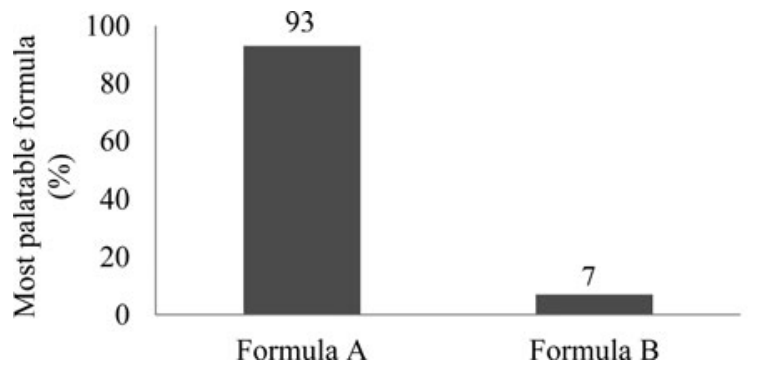

Formula A = extensively hydrolysed whey based, reduced lactose formula Formula B = extensively hydrolysed casein based lactose free formula

In conclusion, the majority of the healthcare professionals in this study reported that the whey hydrolysate with reduced lactose was more palatable than the casein based lactose free hydrolysate. Palatability is an important factor to consider in the management of cows' milk allergy in formula fed infants, to help achieve adequate intakes to support healthy growth and development.

1. Wang J, Sampson HA. (2009) Food allergy: Recent advances in pathophysiology and treatment. Allergy Asthma Immunoll Res 1, 19-29.

2. Vandenplas Y, Brueton M, Dupont C, et al. (2007) Guidelines for the diagnosis and management of cows' milk protein allergy in infants. Arch Dis Child 92, 902-908.

3. Hill DJ, Firer MA, Shelton MJ, et al. (1986) Manifestations of milk allergy in infancy: clinical and immunologic findings. J Pediatr 109, $207-6$.

4. Fiocchi A, Schünemann HJ, Brozek J, et al. (2010) Diagnosis and rationale for action Against Cow's Milk Allergy (DRACMA). J Allergy Clin Immunol 126, 1119-1128.e12.

5. Mabin D, Sykes A, David T. (1995) Nutritional content of few foods diet in atopic dermatitis. Arch Dis Child 73(3), 208-210. 